\title{
Synthesis of Stable Sols of Layered Titanate Nanoparticles using Dialysis and Applications for Thin Film Preparation
}

\author{
Chun Ming Wen, Takashi Kojima and Naofumi Uekawa*
}

Graduate School of Engineering, Chiba University, 1-33 Yayoi-cho, Inage-ku, Chiba-shi, 263-8522, Japan

\begin{abstract}
Sols with stable dispersion of layered titanate nanoparticles were prepared at $298 \mathrm{~K}$ using dialysis of a mixed solution of ethylene glycol, $\mathrm{TiCl}_{3}$, ammonium carbonate, and $\mathrm{H}_{2} \mathrm{O}_{2}$. Raman spectra of the particles in the obtained sols showed Raman scattering peaks which can be assigned to a layered titanate structure. The stability of the obtained sols depended on the molar ratio of [ammonium carbonate] / [Ti ion]. The molar ratios of 3, 4, and 5 produced transparent yellow stable sols. Peptization of titanium hydroxide precipitate with $\mathrm{H}_{2} \mathrm{O}_{2}$ formed stable sols with dispersion of layered titanate nanoparticles, which had plate - shaped morphology. The obtained sols formed layered titanate thin films on glass substrates easily by drying the sols. Furthermore, when the layered titanate thin films were heated at $773 \mathrm{~K}$ for $1 \mathrm{~h}$, anatase $\mathrm{TiO}_{2}$ thin films were obtained with (101) orientation of crystallites and optical transparency.
\end{abstract}

Keywords: Nanostructures, Oxides, Thin films, Sol-gel, Peptization, Coatings.

\section{INTRODUCTION}

Titanium oxides have potential applications as photocatalysts, as electrical and optical materials, and as coating materials for controlling UV-shielding properties [1, 2]. For these applications, the development of preparation methods for the titanium oxide thin films with simple processes is an important issue because it is necessary to prepare titanium oxide thin films on many different types of substrates such as glasses and organic polymers [3]. Applications as photocatalysts and dye-sensitized solar cells require titanium oxide thin films having a nanoporous surface $[4,5]$. Accordingly, to prepare titanium oxide thin films, stable sols with dispersion of titanium oxide nanoparticles are suited for use as coating materials because drying of the sols on the substrates can produce thin films. Furthermore, when titanium oxide nanoparticles with controlled shapes such as sheet or plate are coated onto a substrate, the obtained films have the orientation of the crystallites, which depends on the nanoparticle morphology [6-8]. Particularly, the sheet or plate morphology of the nanoparticles is suited for the thin film preparation [9, 10]. Development of stable sols of the shape controlled titanium oxide nanoparticles remains as an important issue [11]. Here, layered titanate particles have sheet or plate morphology can be transformed to $\mathrm{TiO}_{2}$ by heating at more than $673 \mathrm{~K}$. Therefore, the sols with stable dispersion of layered titanate particles are useful as good coating materials for $\mathrm{TiO}_{2}$ thin films.

*Address correspondence to this author at the Graduate School of Engineering, Chiba University, 1-33 Yayoi-cho, Inage-ku, Chiba-shi, 263-8522, Japan; Tel: +81-43-290-3373; Fax: +81-43-290-3401;

E-mail: uekawa@faculty.chiba-u.jp
Ichinose et al. synthesized peroxo-modified anatase sols by peptization of titanium hydroxide (IV) gel with $\mathrm{H}_{2} \mathrm{O}_{2}$ aqueous solution [12]. This process requires that the titanium hydroxide gels are purified by washing using a centrifuge. Ban et al. synthesized a colloidal solution of layered titanate by mixing titanium isopropoxide and tetramethylammonium hydroxide aqueous solution at room temperature [13, 14]. These sols are useful for anatase nanoparticles and for hybrid inorganic-organic films. Furthermore, layered titanate nanoparticles and their sols have been used intensively as precursors for the preparation of anatase $\mathrm{TiO}_{2}$ nanorods and nanotubes. Layered titanate particles with sheet or plate morphology are appropriate for thin film preparation with crystallite orientation [15].

In this study, a novel, simple, and high-yield preparation method for layered titanate sols was investigated. To achieve that aim, a one-pot synthetic process was examined, involving mixing of titanium chloride, a base aqueous solution, and a $\mathrm{H}_{2} \mathrm{O}_{2}$ aqueous solution. The addition of $\mathrm{H}_{2} \mathrm{O}_{2}$ enables stabilization of the obtained sol by formation of a peroxo complex. Dialysis of the obtained sol with a cellulose tube is used to remove impurity ions such as chloride ions and base molecules. These processes did not include the separation of precipitates. Furthermore, $\mathrm{TiO}_{2}$ thin film preparation by coating the layered titanate sols was examined.

\section{EXPERIMENTS}

\subsection{Preparation of Layered Titanate Sol}

Sols of layered titanate particles were prepared as follows: $3.85 \mathrm{~g}$ of titanium chloride (III) $\left(\mathrm{TiCl}_{3}\right)$ aqueous solution $\left(20 \mathrm{wt} \%, \mathrm{Ti}^{3+} 0.005 \mathrm{~mol}\right)$ was dissolved in 10 
$\mathrm{mL}$ of ethylene glycol. The $2.4 \mathrm{~g}(0.025 \mathrm{~mol})$ of ammonium carbonate $\left(\mathrm{NH}_{4}\right)_{2} \mathrm{CO}_{3}$ was dissolved in 10 $\mathrm{mL}$ of $\mathrm{H}_{2} \mathrm{O}$. This aqueous solution was mixed with an ethylene glycol solution of $\mathrm{TiCl}_{3}$. After the formation of a titanium hydroxide precipitate, deionized water was added to the solution and the volume was adjusted to $50 \mathrm{~mL}$. The $5.67 \mathrm{~g}$ of $30 \mathrm{wt} \%$ hydrogen peroxide $\left(\mathrm{H}_{2} \mathrm{O}_{2}\right)$ aqueous solution was added to the solution. The hydroxide precipitate was spontaneously peptized, producing a clear yellow solution. The solution was packed in a cellulose tube to be dialyzed in $\mathrm{H}_{2} \mathrm{O}$. After the dialysis, yellow clear sols were obtained. The whole preparation process was conducted at room temperature. The obtained sols were dried at $328 \mathrm{~K}$ for $24 \mathrm{~h}$ to obtain powder samples. This synthetic procedure was also conducted using the molar ratio of [ammonium carbonate] / [ $\mathrm{Ti}$ ion] from 0 to 5. The preparation of the solutions and sols with different [ammonium carbonate] / [ $\mathrm{Ti}$ ion] molar ratios was carried out over five times at each molar ratio. The obtained sols and solutions had same characteristics when the molar ratios of [ammonium carbonate] / [Ti ion] were equal. All chemicals used in this preparation were of reagent grade (Wako Pure Chemical Industries Ltd.).

\subsection{Thin Film Preparation by Coating Sols onto a Glass Substrate}

The $10 \mathrm{~mL}$ of the obtained sol and $10 \mathrm{~mL}$ of $\mathrm{H}_{2} \mathrm{O}$ were poured into a glass dish of $10.0 \mathrm{~cm}$ diameter. A square alkali-free glass plate $(50 \mathrm{~mm} \times 50 \mathrm{~mm} \times 1 \mathrm{~mm})$ was put on the glass dish, which was heated at $328 \mathrm{~K}$ for $12 \mathrm{~h}$ to dry. Finally, the layered titanate thin film on the alkali-free glass plate was obtained. The obtained thin films with the substrates were fired under air atmosphere at $773 \mathrm{~K}$ for $1 \mathrm{~h}$ to obtain $\mathrm{TiO}_{2}$ thin films.

\subsection{Characterization}

Structures of the obtained particles and films were characterized using X-ray diffraction (XRD) ( $\mathrm{Cu} \mathrm{K \alpha} 40$ kV, 15 mA, Mini Flex; Rigaku Corp.) with a Ni filter. The particle shape was observed using field emission scanning electron microscopy (FE-SEM, JSM-6330; JEOL Ltd.) after Os coating. The ultraviolet-visible (UV-VIS) spectra of the sols and the solutions were measured using a quartz cell (UV2000; Shimadzu Corp.) with wavelengths of $300-800 \mathrm{~nm}$. The TG-DTA curves were measured (thermo plus EVO II; Rigaku Corp.). Raman spectra of the powders obtained by drying the sols were measured using NRS-2100, Jasco Ltd.

\section{RESULTS AND DISCUSSION}

\subsection{Effects of Ammonium Carbonate Added to $\mathrm{TiCl}_{3}$ Solution during Layered Titanate Sol Formation}

Figure 1 exhibits XRD patterns of the particles obtained by drying the sols, which were prepared by dialysis of the mixed solution among $\mathrm{TiCl}_{3}$, ammonium carbonate, and $\mathrm{H}_{2} \mathrm{O}_{2}$ with different [ammonium carbonate]/[Ti ion] molar ratios. The XRD peaks whose $2 \theta$ values were less than $10^{\circ}$ were observed and the peaks corresponded to X-ray diffraction of the interlayer of a layered titanate structure. The Miller index of the peak can be assigned to $(020)[16,17]$. When the [ammonium carbonate]/[Ti ion] molar ratio was 2 , as presented in Figure $\mathbf{1 b}$, the XRD peak below $2 \theta=10^{\circ}$ became broader than the other [ammonium carbonate]/[Ti ion] molar ratios.

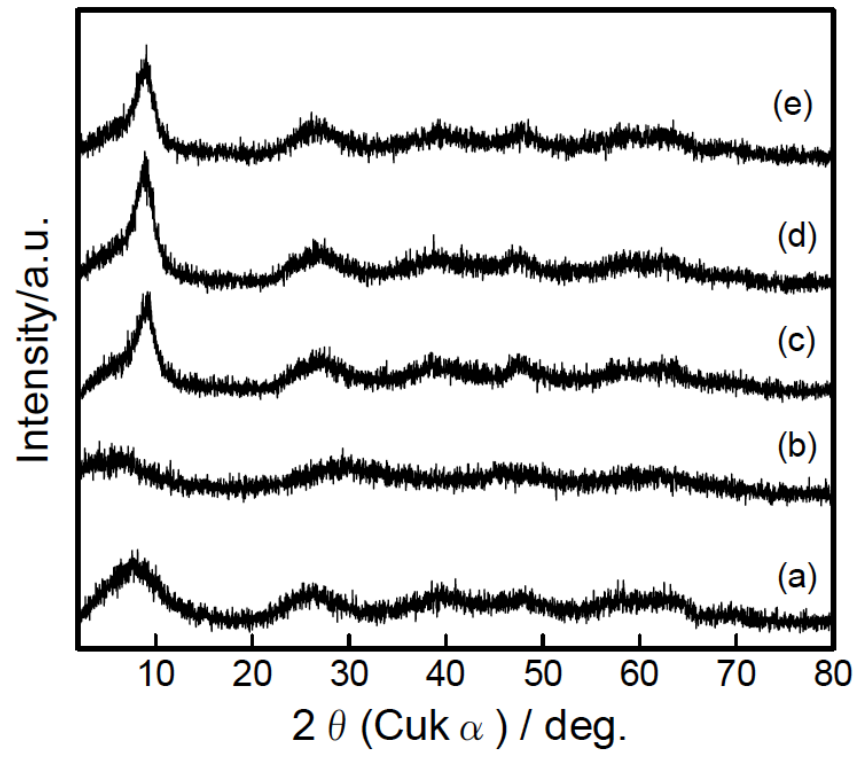

Figure 1: XRD patterns of the particles obtained using dialysis of the mixed solutions of ethylene glycol solution of $\mathrm{TiCl}_{3}$, ammonium carbonate aq, and $\mathrm{H}_{2} \mathrm{O}_{2}$ with the change of [ammonium carbonate]/[Ti ion] molar ratio. The molar ratios of [ammonium carbonate]/[Ti ion] were (a) 1, (b) 2, (c) 3, (d) 4 , and (e) 5 .

To investigate formation of the layered titanate structure, Raman spectra were measured as presented in Figure 2. Peaks in the Raman spectra of Figures 2a and $2 \mathrm{c}-2 \mathrm{e}$, with Raman shift wavenumbers around 279 $\mathrm{cm}^{-1}, 500 \mathrm{~cm}^{-1}$, and $672 \mathrm{~cm}^{-1}$, can be assigned to the symmetric $A_{g}$ modes as a well-developed $2 D$ layered structure [17, 18]. Accordingly, the layered titanate particles were obtained by simply mixing the solutions and dialysis process at room temperature. Furthermore, Raman peaks around $900 \mathrm{~cm}^{-1}$ can be 
assigned to the peroxo groups, which affected the dispersed state of the obtained layered titanate particles in the sols $[19,20]$. However, the Raman spectrum of the powders obtained with [ammonium carbonate $] /[\mathrm{Ti}$ ion $]=2$ as presented in Figure $\mathbf{2} \mathbf{b}$ had no clear Raman peak. This result agreed with that of the $X R D$ pattern in Figure 1 $\mathbf{b}$. The phenomenon related to the change of the chemical species in the mixed solution with increase of the added amount of ammonium carbonate.

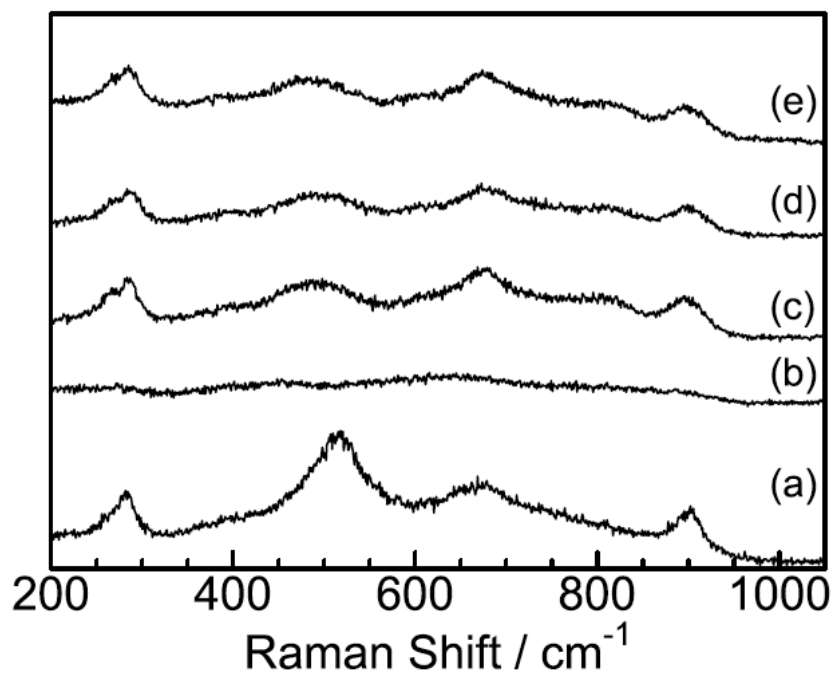

Figure 2: Raman spectra of the particles obtained using dialysis of the mixed solutions of ethylene glycol solution of $\mathrm{TiCl}_{3}$, ammonium carbonate aq, and $\mathrm{H}_{2} \mathrm{O}_{2}$ with the change of [ammonium carbonate]/[Ti ion] molar ratio. The molar ratios of [ammonium carbonate]/[Ti ion] were (a) 1, (b) 2, (c) 3, (d) 4 , and (e) 5 .

Evaluation of the dispersed state of the particles in the obtained sols is an extremely important issue for application as a coating solution of titanium oxide thin films. Figure 3 presents the UV-VIS transmittance spectra and photographs of the obtained sols. When the [ammonium carbonate]/[Ti ion] values were 1 and 2 , the optical transmittance of the obtained sols was 0 , with wavelengths of $300-800 \mathrm{~nm}$, as shown in Figures 3a and $\mathbf{3 b}$. Photographs of the obtained yellow opaque sols are also shown in Figure 3. Light scattering, which corresponds to the aggregated particles in the sols, caused low optical transmittance. However, when the [ammonium carbonate]/[Ti ion] values were more than 3 , the UV-VIS transmittance was higher than $75 \%$, with wavelengths of $450-800 \mathrm{~nm}$, as shown in Figures 3c3e. This high transmittance indicates that clear and stable sols were obtained. The obtained sols were transparent and yellow. The yellow color of the obtained sols after dialysis, as shown in Figures $3 c-3 e$, corresponded to the surface peroxo groups, as discussed for the Raman spectra in Figure 2. The dispersed state and transparency of the obtained sols depended on the added amount of the ammonium carbonate into the ethylene glycol solution of $\mathrm{TiCl}_{3}$.

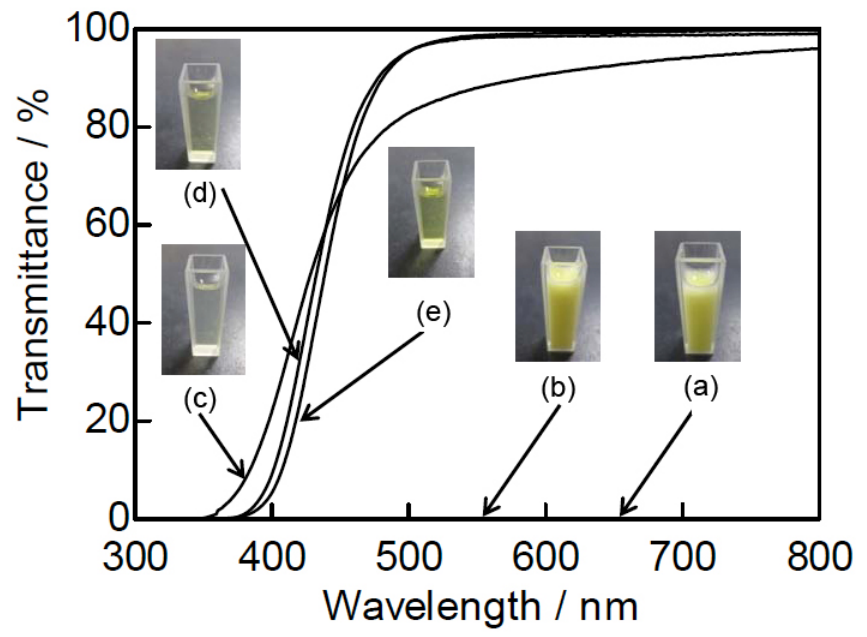

Figure 3: UV-VIS transmittance spectra of the sols obtained using dialysis of the mixed solutions of ethylene glycol solution of $\mathrm{TiCl}_{3}$, ammonium carbonate aq, and $\mathrm{H}_{2} \mathrm{O}_{2}$ with the change of [ammonium carbonate]/[Ti ion] molar ratio. The molar ratios of [ammonium carbonate]/[Ti ion] were (a) 1 , (b) 2, (c) 3, (d) 4, and (e) 5 .

The particle morphology in the obtained sols was examined using FE-SEM measurements. Figure 4 shows FE-SEM images of particles in the powders obtained by drying the sols. For [ammonium carbonate $] /[\mathrm{Ti}$ ion $]=1$ and 2 , the aggregate structures of the particles were observed with average diameter of $210 \mathrm{~nm}$ and $86 \mathrm{~nm}$, respectively. However, when the [ammonium carbonate]/[Ti ion] values were more than 3 , the particle morphology exhibited strong aggregation of thin plate particles with average diameter of $45 \mathrm{~nm}$, as shown in Figures $\mathbf{4 c}$ and $\mathbf{4 d}$. The plate morphology of the layered titanate nanoparticles in the obtained sols was appropriate for thin film preparation. The condition of [ammonium carbonate]/[Ti ion] $=2$ was the crucial stage at which the aggregated morphology of the obtained nanoparticles changed.

To investigate the effect of the added amount of ammonium carbonate on formation of the sols, UV-VIS absorption spectra of the mixed solutions of the ethylene glycol solution of $\mathrm{TiCl}_{3}$, ammonium carbonate aq, and $\mathrm{H}_{2} \mathrm{O}_{2}$ were measured. The solutions were diluted with $\mathrm{H}_{2} \mathrm{O}$ by 50 times immediately after the mixing process in order to measure the optical absorbance of the mixed solution. Figure $\mathbf{5 a}$ shows the UV-VIS absorbance spectrum of the solution obtained with [ammonium carbonate]/[Ti ion] $=1$. The absorption peak around $350 \mathrm{~nm}$ corresponds to the Ti-peroxo 
(a)

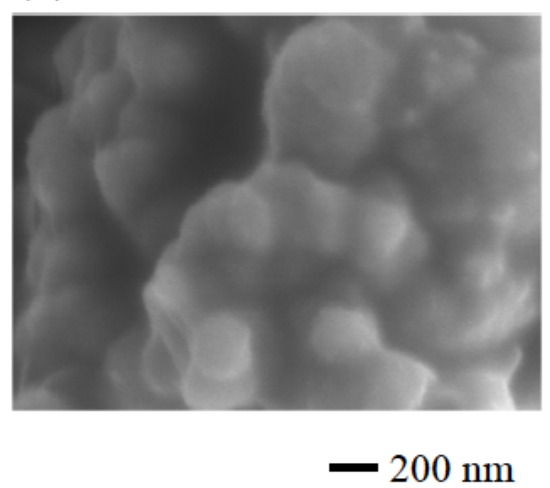

(c)

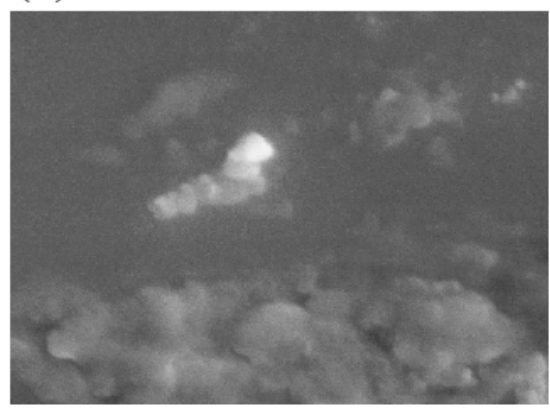

$-200 \mathrm{~nm}$ (b)

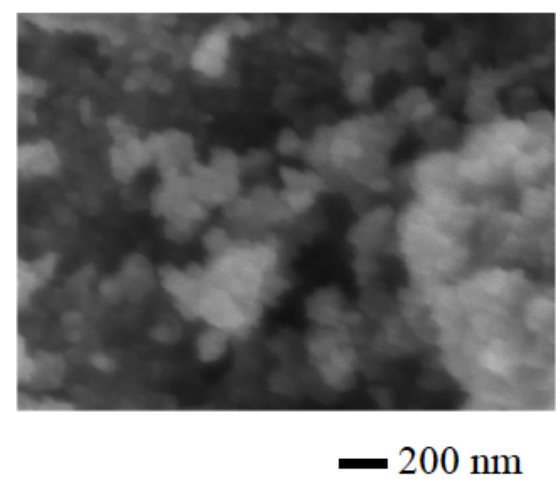

(d)

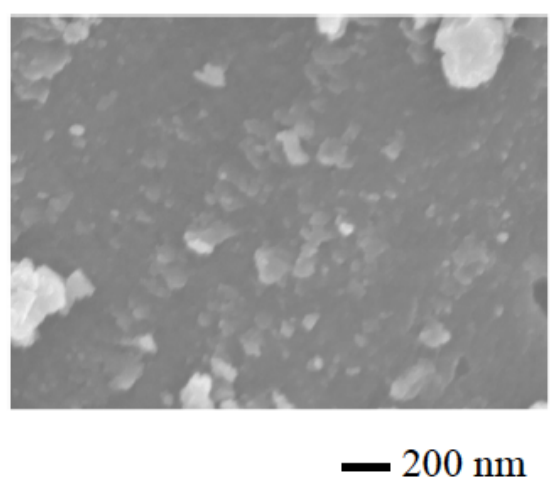

Figure 4: FE-SEM images of the sols obtained using dialysis of the mixed solutions of ethylene glycol solution of $\mathrm{TiCl}_{3}$, ammonium carbonate aq, and $\mathrm{H}_{2} \mathrm{O}_{2}$ with the change of [ammonium carbonate]/[Ti ion] molar ratio. The molar ratios of [ammonium carbonate]/[Ti ion] were (a) 1, (b) 2, (c) 3, (d) 4, and (e) 5 .

complex molecules [21]. Strong absorption with wavelength of less than $300 \mathrm{~nm}$ resulted from charge transfer absorption between the $\mathrm{Ti}$ ion and oxygen ion.

When the value of [ammonium carbonate]/[Ti ion] was 2, as presented in Figure $\mathbf{5 b}$, the absorption peak of the Ti-peroxo complex became broad. Furthermore, when the value of [ammonium carbonate]/[Ti ion] was greater than 3, as shown in Figures $\mathbf{5 c - 5 e}$, the intensity of the absorption peak of the Ti-peroxo complex around $350 \mathrm{~nm}$ became weak. Only the charge transfer absorption between $\mathrm{Ti}$ ion and oxygen ion appeared which indicated that little free Ti-peroxo complex existed in the mixed solution before the dialysis. Furthermore, the mixed solution did not penetrate the cellulose tube during the dialysis and it indicated that nanoparticles were formed in the mixed solution.

The addition of different amount of ammonium carbonate affects the $\mathrm{pH}$ value of the mixed solution between titanium chrolide (III) and ammonium carbonate aq. When the values of [ammonium carbonate]/[Ti ion] were 1 and 2, the mixed solutions were under an acidic condition. In this condition, aquo complex ions of $\mathrm{Ti}$ ions were in the mixed solution and the $\mathrm{H}_{2} \mathrm{O}_{2}$ reacted with the $\mathrm{Ti}$ ions. On the other hand, when the values of [ammonium carbonate]/[Ti ion] were

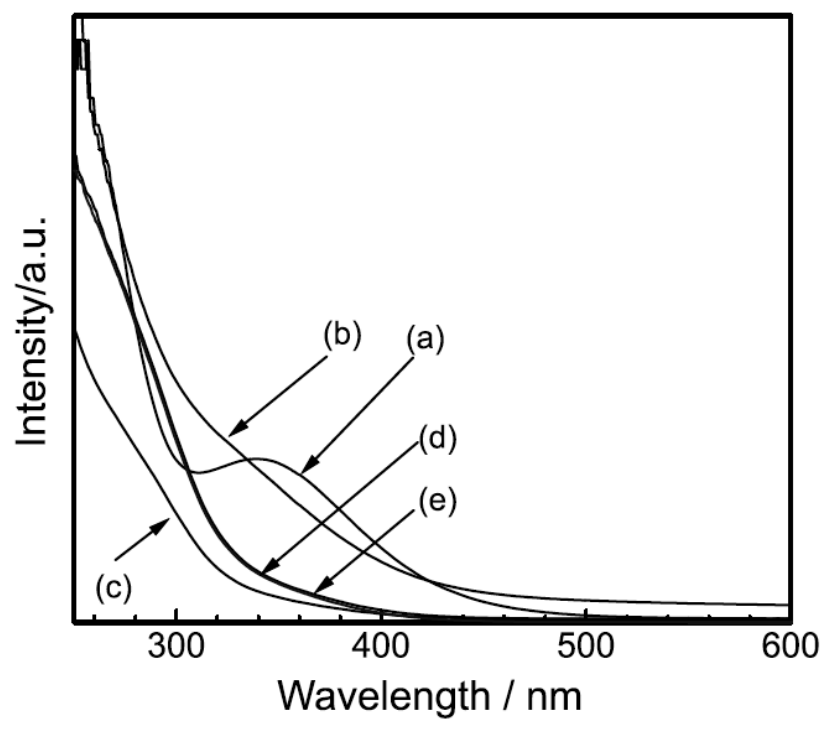

Figure 5: UV-VIS absorption spectra of the mixed solutions of ethylene glycol solution of $\mathrm{TiCl}_{3}$, ammonium carbonate aq, and $\mathrm{H}_{2} \mathrm{O}_{2}$ with change of [ammonium carbonate]/[Ti ion] molar ratio. The solutions were distilled 50 times with $\mathrm{H}_{2} \mathrm{O}$ before the measurement. The molar ratios of [ammonium carbonate]/[Ti ion] were (a) 1, (b) 2, (c) 3, (d) 4, and (e) 5 . 
more than 3 , the solutions were under a basic condition. In this condition, $\mathrm{Ti}$ hydroxide precipitate were formed at first and the $\mathrm{H}_{2} \mathrm{O}_{2}$ molecules reacts with the hydroxide precipitate to cause the peptization process at room temperature, forming layered titanate nanoparticles with stable dispersion, as shown in Figures 3c-3e. However, for [ammonium carbonate]/[Ti ion]=1 and 2, the free Ti-peroxo complex ions were present in the mixed solution. During dialysis, quick hydrolysis reaction of the Ti-peroxo complex ions proceeded to form the aggregated morphology of the layered titanate nanoparticles. In particular, when the values of [ammonium carbonate]/[Ti ion] were 2 , the both of the Ti-peroxo complex ions and the peptized substances of the Ti hydroxide precipitate coexisted in the solution before the dialysis so that the amorphous phase was obtained after the dialysis.

Accordingly, the added amount of the ammonium carbonate into the ethylene glycol solution of $\mathrm{TiCl}_{3}$ affected the dispersed state of the obtained particles after the dialysis. Since the Raman spectra of the obtained powders showed the peak around $900 \mathrm{~cm}^{-1}$ which can be assigned to the peroxo groups as shown in Figure 2, the peroxo groups which coordinated to the $\mathrm{Ti}$ ions are relatively stable. The particles obtained after the drying also contained the peroxo groups on the surface of the particles so that the negatively charged peroxo groups played the important role for the stable dispersion of the layered particles in the sols.

\subsection{Characterization of Titanium Oxide Thin Films Obtained by Coating Layered Titanate Sols}

The layered titanate particles dispersed in the sols had plate morphology. Therefore, the particles are expected to be suitable for thin film preparation. Sols prepared with [ammonium carbonate] $/[\mathrm{Ti}$ ion] $=5$ were coated onto the sodium free glass substrate. Figure 6 shows XRD patterns of the obtained thin films. The XRD peaks around $2 \theta=9^{\circ}$ correspond to the diffraction of the basal inter-layer (020) series of layered titanate structure. The broad peak around $2 \theta=25^{\circ}$ corresponds to the glass substrate. Accordingly, the layered titanate nanoparticles in the sols were stacked on the glass substrate to be parallel with $(020)$ of them, so that the (020) crystallite orientation occurred in the obtained layered titanate thin films.

To obtain $\mathrm{TiO}_{2}$ thin films, the layered titanate thin films were heated at $773 \mathrm{~K}$ for $1 \mathrm{~h}$ for each coating procedure. The XRD patterns are presented in Figure 7. All XRD peaks can be assigned to anatase $\mathrm{TiO}_{2}$.

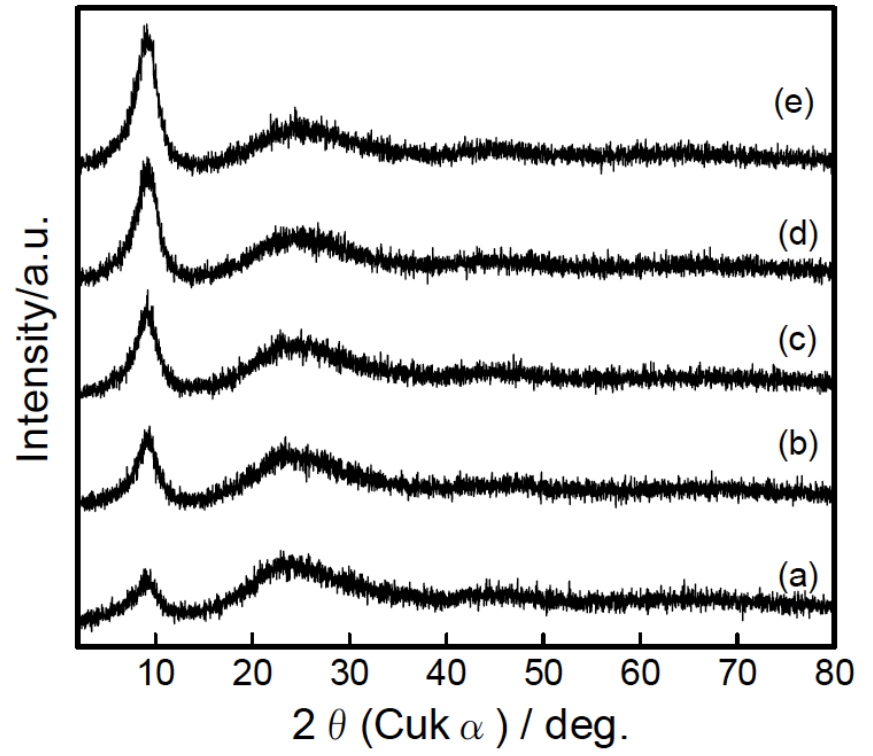

Figure 6: XRD patterns of the thin films prepared by drying the sol on an alkali free glass substrate with [ammonium carbonate $] /[\mathrm{Ti}$ ion $]=5$ (molar ratio) at $328 \mathrm{~K}$ for $12 \mathrm{~h}$. The coating times were (a) 1, (b) 2, (c) 3, (d) 4, and (e) 5 .

When the coating times increased, only the peak intensities of (101), (103), (105), and (204) increased. Particularly the diffraction peak intensity of (101) was strong compared with the other diffraction peaks, which indicates the thin films have the (101) orientation of anatase $\mathrm{TiO}_{2}$ crystallites. The oriented aggregation of the layered titanate plate particles in the thin films transformed to anatase nanoparticles by firing at $773 \mathrm{~K}$

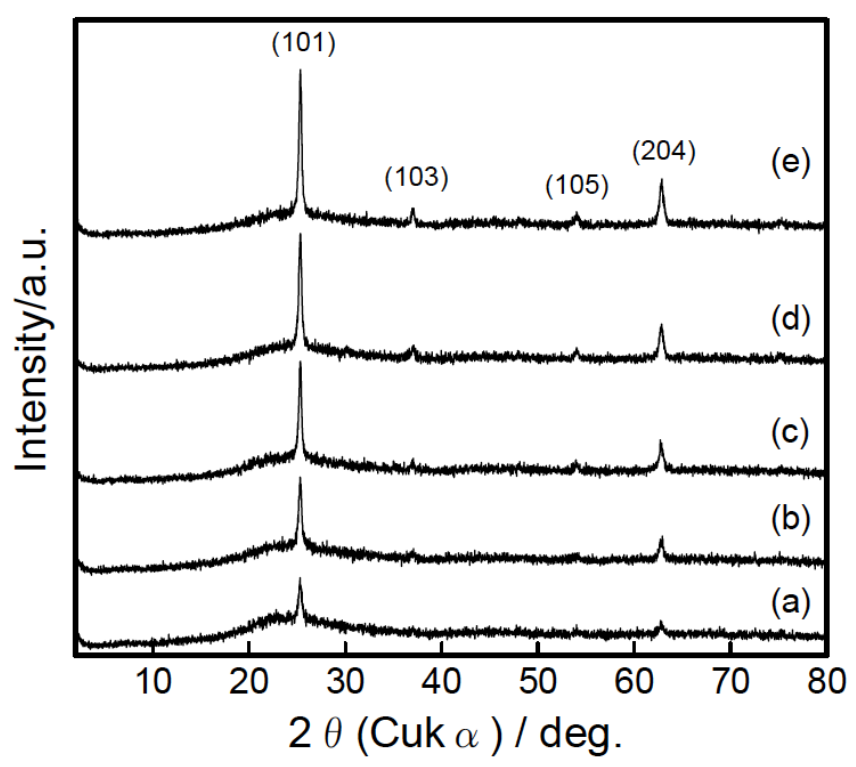

Figure 7: XRD patterns of the thin films prepared by repeating drying the sol on the substrate and firing the thin films at $773 \mathrm{~K}$ for $1 \mathrm{~h}$. The sol used for the coating was obtained with [ammonium carbonate] $/[\mathrm{Ti}$ ion] $=5$ (molar ratio). The numbers of coating procedures were (a) 1 , (b) 2 , (c) 3, (d) 4, and (e) 5 . 
for $1 \mathrm{~h}$. The (101) orientation of anatase $\mathrm{TiO}_{2}$ crystallites occurred in the thin films. Furthermore, the (101) of anatase $\mathrm{TiO}_{2}$ is most thermodynamically stable and this also related to the (101) orientation [22, 23].

Figure 8 shows UV-VIS transmittance spectra of the thin films obtained by firing the layered titanate thin films at $773 \mathrm{~K}$ for $1 \mathrm{~h}$ for each coating procedures. For one coating procedure, as presented in Figure $\mathbf{8 a}$, the optical transmittance of the thin film decreased steeply at wavelengths shorter than $350 \mathrm{~nm}$. This phenomenon resulted from the electron transition between band gaps of anatase $\mathrm{TiO}_{2}$. However, when the wavelength was longer than $400 \mathrm{~nm}$, the value of the optical transmittance was greater than $75 \%$. Figures $\mathbf{8 b}$ and 8c show transmittance spectra of the $\mathrm{TiO}_{2}$ thin films with 3 and 5 coating procedures. When the wavelength was longer than $400 \mathrm{~nm}$, the optical transmittance was greater than $75 \%$, even though the number of the coating procedures increased. Accordingly, the anatase $\mathrm{TiO}_{2}$ thin films obtained by firing the layered titanate thin films coated with the sols has a homogeneous texture without light scattering. Furthermore, the dependence of the transmittance on the wavelength resulted from interference between the penetrated light of the thin films and the reflected light on the interface. This dependence on the wavelength is also related to the dense packing of the crystallites in the thin films.

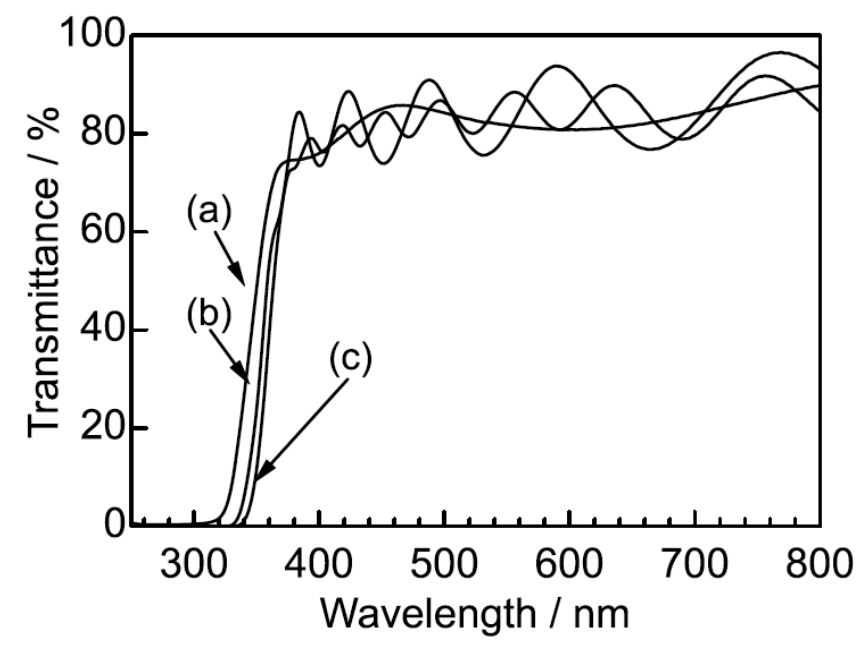

Figure 8: UV-VIS transmittance spectra of the thin films prepared by repeating drying the sol on the substrate and firing the thin films at $773 \mathrm{~K}$ for $1 \mathrm{~h}$. The sol used for the coating was obtained with [ammonium carbonate] $/[\mathrm{Ti}$ ion] $=5$ (molar ratio). The numbers of coating procedures were (a) 1 , (b) 3 , and (c) 5 .

Figure 9 portrays FE-SEM images of the thin films prepared by repeating drying of the layered titanate sols obtained with [ammonium carbonate] $/[\mathrm{Ti}$ ion] $=5$ (a)

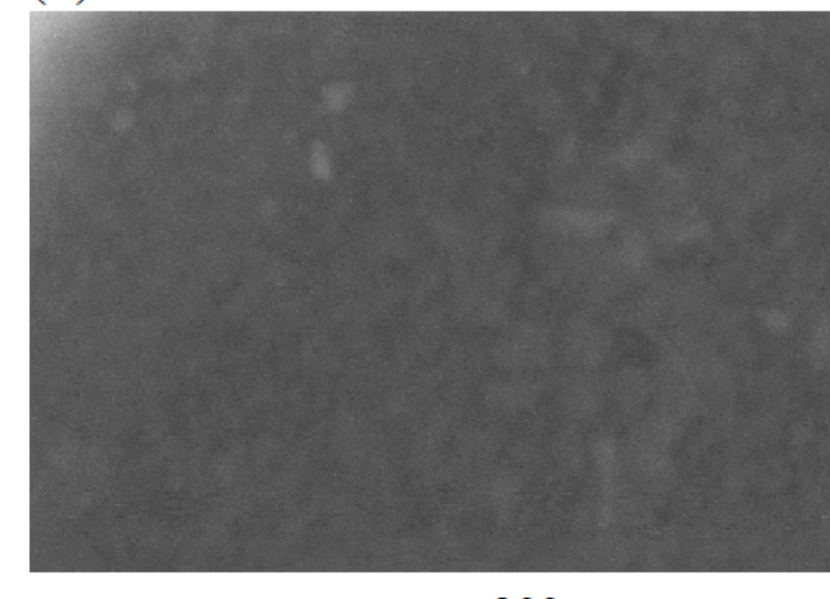

$200 \mathrm{~nm}$

(b)

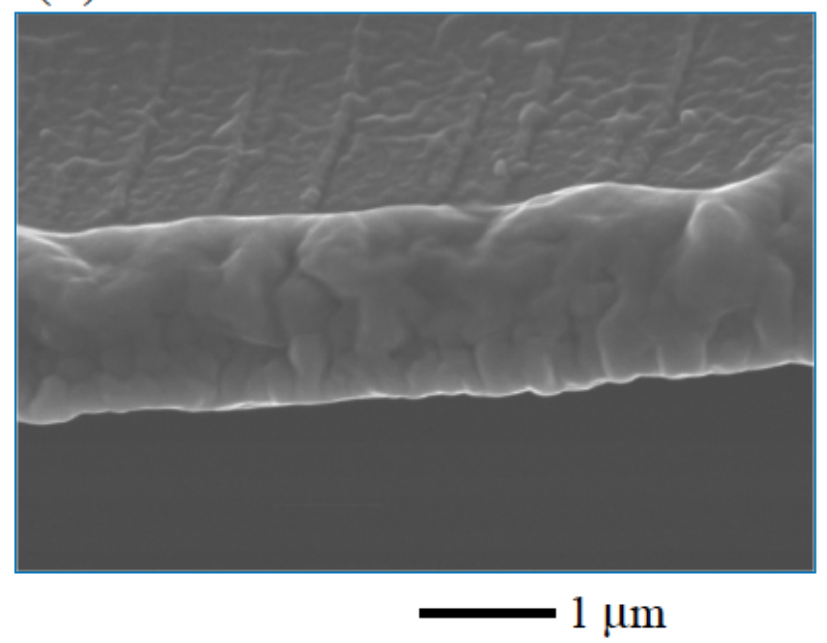

Figure 9: SEM images of the anatase $\mathrm{TiO}_{2}$ thin films prepared by repeating drying the sol on the substrate and firing the thin films at $773 \mathrm{~K}$ for $1 \mathrm{~h}$. The sol used for the coating was obtained with [ammonium carbonate] $/[\mathrm{Ti}$ ion] $=5$ (molar ratio). Five coating procedures were used.

(a) SEM image of the surface of the obtained thin film.

(b) SEM image of the cross section of the obtained thin film.

(molar ratio) and firing of the thin films at $773 \mathrm{~K}$ for $1 \mathrm{~h}$. Five coating procedures were used. The thin film surface showed morphology of the aggregated $\mathrm{TiO}_{2}$ nanoparticles with average diameter of $40 \mathrm{~nm}$, as shown in Figure 9a. Furthermore, the thin film thickness was $1250 \mathrm{~nm}$, as shown in Figure 9b. Accordingly, both the surface and the cross section of the thin film exhibited dense morphology with the $\mathrm{TiO}_{2}$ nanoparticles. The plate and sheet morphology of the layered titanate nanoparticles in the obtained sols enabled packing with dense aggregation of the nanoparticles. Furthermore, drying the layered titanate sols on a glass substrate made it possible to obtain 
layered titanate thin films and anatase $\mathrm{TiO}_{2}$ thin films with a homogeneous texture. Accordingly, the layered titanate sols obtained by only dialysis of the mixed solutions of ethylene glycol solution of $\mathrm{TiCl}_{3}$, annmonium carbonate aq, and $\mathrm{H}_{2} \mathrm{O}_{2}$ enabled us to make anatase $\mathrm{TiO}_{2}$ thin films with (101) orientation with simple drying and firing process on glass substrate.

\section{CONCLUSION}

Sols with stable dispersion of the layered titanate nanoparticles were prepared using dialysis of the mixed solution of ethylene glycol, $\mathrm{TiCl}_{3}$, ammonium carbonate, and $\mathrm{H}_{2} \mathrm{O}_{2}$ at $298 \mathrm{~K}$. Raman spectra and the FE-SEM images of the particles in the obtained sols indicate that the plate-shaped layered titanate nanoparticles are included in the sols. The stability of the obtained sols depended on the molar ratio of [ammonium carbonate] / [Ti ion]. When the molar ratios were 1 and 2, precipitation occurred during the dialysis process with the cellulose tube. However, transparent yellow stable sols were obtained when the molar ratios were 3,4 , and 5 . The difference of the stability of the obtained sols depended on the target chemical species of the reaction with $\mathrm{H}_{2} \mathrm{O}_{2}$. The peptization of titanium hydroxide precipitate with $\mathrm{H}_{2} \mathrm{O}_{2}$ formed stable sols with dispersion of layered titanate nanoparticles without using a cseparation process of the hydroxide precipitates. The obtained sols formed layered titanate thin films on the glass substrate easily by drying of the sols. Furthermore, when the layered titanate thin films were heated at $773 \mathrm{~K}$ for $1 \mathrm{~h}$, the anatase $\mathrm{TiO}_{2}$ thin films with (101) orientation of crystallites and optical transparency are obtainable.

\section{REFERENCES}

[1] Pang YL, Lim S, Ong HC, Chong WT. A critical review on the recent progress of synthesizing techniques and fabrication of $\mathrm{TiO}_{2}$-based nanotubes photocatalysts. Appl Catal A: General 2014; 481: 127-42.

http://dx.doi.org/10.1016/j.apcata.2014.05.007

[2] Liua N, Chena X, Zhangb J, Schwanka JW. A review on $\mathrm{TiO}_{2}$-based nanotubes synthesized via hydrothermal method: Formation mechanism, structure modification, and photocatalytic applications. Catal Today 2014; 225: 34-51. http://dx.doi.org/10.1016/j.cattod.2013.10.090

[3] Fretwell R, Douglas P. An active, robust and transparent nanocrystalline anatase $\mathrm{TiO}_{2}$ thin film -preparation, characterisation and the kinetics of photodegradation of model pollutants. J Photochem Photobiol A Chem 2001; 143: 229-40. http://dx.doi.org/10.1016/S1010-6030(01)00526-3

[4] O'Regan B, Grätzel M. A low-cost, high-efficiency solar cell based on dye-sensitized colloidal $\mathrm{TiO}_{2}$ films. Nature 1991; 353: $737-40$.

http://dx.doi.org/10.1038/353737a0
[5] Kavan L, Grätzel M, Gilbert SE, Klemenz C, Scheel HJ. Electrochemical and photoelectrochemical investigation of single-crystal anatase. J Am Chem Soc 1996; 118: 6716-23. http://dx.doi.org/10.1021/ja954172/

[6] Tian ZR, Voigt JA, Liu J, Mckenzie B, Xu H. Large oriented arrays and continuous films of $\mathrm{TiO}_{2}$-based nanotubes. J Am Chem Soc 2003; 125: 12384-5.

http://dx.doi.org/10.1021/ja0369461

[7] Hosono E, Matsuda H, Honma I, Ichihara M, Zhou H. Synthesis of a perpendicular $\mathrm{TiO}_{2}$ nanosheet film with the superhydrophilic property without UV irradiation. Langmuir 2007; 23: 7447-50.

http://dx.doi.org/10.1021/la701117a

[8] Ohgi H, Maeda T, Hosono E, Fujihara S, Imai H. Evolution of nanoscale $\mathrm{SnO}_{2}$ grains, flakes, and plates into versatile particles and films through crystal growth in aqueous solutions. Cryst Growth Des 2005; 5: 1079-83. http://dx.doi.org/10.1021/cg049644z

[9] Uekawa N, Saito T, Kojima T, Kakegawa K. J Mater Lett 2012; 86: 125-8.

http://dx.doi.org/10.1016/j.matlet.2012.07.047

[10] Gao YF, Nagai M, Masuda Y, Sato F, Seo WS, Koumoto K Surface precipitation of highly porous hydrotalcite-like film on Al from a zinc aqueous solution. Langmuir 2006; 22: 3521-7. http://dx.doi.org/10.1021/la052424i

[11] Ogawa F, Ban T, Ohya Y. Preparation of lamellar hybrid inorganic-organic films of layered titanate and cationic or anionic surfactants. Thin Solid Films 2008; 516: 4863-7. http://dx.doi.org/10.1016/j.tsf.2007.09.007

[12] Ichinose $H$, Terasaki $M$, Katsuki $H$. Synthesis of peroxomodified anatase sol from peroxo titanic acid solution. Ceram Soc Jpn 1996; 104: 715-8. http://dx.doi.org/10.2109/jcersj.104.715

[13] Ban T, Yoshikawa S, Ohya Y. Synthesis of transparent aqueous sols of colloidal layered niobate nanocrystals at room temperature. J Colloid Interface Sci 2011; 364: 85-91. http://dx.doi.org/10.1016/j.jcis.2011.08.026

[14] Ban T, Kondoh S, Ohya T, Ohya $Y$, Takahashi $Y$. Photocatalysis of a transparent titanate aqueous sol prepared from titanium tetraisopropoxide and tetramethyl ammonium hydroxide. J Photochem Photobiol A Chem 2003; 156: 219-25. http://dx.doi.org/10.1016/S1010-6030(02)00404-5

[15] Taira K, Hirose Y, Nakao S, et al. ACS Nano 2014; 8: 614550.

http://dx.doi.org/10.1021/nn501563j

[16] Gao T, Fjellvag $\mathrm{H}$, Norby $\mathrm{P}$. Raman scattering properties of a protonic titanate $\mathrm{H}_{x} \mathrm{Ti}_{2-x / 4 \square \times / 4} \mathrm{O}_{4} \cdot \mathrm{H}_{2} \mathrm{O}(\square$, vacancy; $x=0.7$ ) with lepidocrocite-type layered structure. J Phys Chem B 2008; 112: $9400-5$

http://dx.doi.org/10.1021/jp801639a

[17] Ma R, Bando Y, Sasaki T. Nanotubes of lepidocrocite titanates. Chem Phys Lett 2003; 380: 577-82.

http://dx.doi.org/10.1016/j.cplett.2003.09.069

[18] Ivanova S, Penkova A, Hidalgo MC, et al. Synthesis and application of layered titanates in the photocatalytic degradation of phenol. Appl Catal B Environmental 2015; 163: 23-9.

http://dx.doi.org/10.1016/j.apcatb.2014.07.048

[19] Gao T, Fjellvag H, Norby P. Crystal structures of titanate nanotubes: a Raman scattering study. Inorg Chem 2009; 48: 1423-32.

http://dx.doi.org/10.1021/ic801508k

[20] Nour EM. Inorg Chimica Acta 1986; 117: 45-8. http://dx.doi.org/10.1016/S0020-1693(00)88064-0

[21] Mühlebach J, Müller K, Schwarzenbach G. The peroxo complexes of titanium. Inorg Chem 1970; 9: 2381-90. http://dx.doi.org/10.1021/ic50093a001 
[22] Chen C, Xu L, Sewvandi GA, et al. Cryst Growth Des 2014; 14: $5801-11$.

http://dx.doi.org/10.1021/cg501062r
[23] Gong XQ, Selloni A, Batzill M, Diebold U. Steps on anatase $\mathrm{TiO}_{2}$ (101). Nat Mater 2006; 5: 665-70.

http://dx.doi.org/10.1038/nmat1695

Received on 14-10-2015

Accepted on 25-11-2015

Published on 18-12-2015

DOI: http://dx.doi.org/10.6000/1929-5030.2015.04.04.1

(c) 2015 Wen et al.; Licensee Lifescience Global.

This is an open access article licensed under the terms of the Creative Commons Attribution Non-Commercial License (http://creativecommons.org/licenses/by-nc/3.0/) which permits unrestricted, non-commercial use, distribution and reproduction in any medium, provided the work is properly cited. 